\title{
The Perry Initiative's Impact on Gender Diversity Within Orthopedic Education
}

\author{
Delaney Harbold ${ }^{1} \cdot$ Laurie Dearolf $^{2} \cdot$ Jennifer Buckley $^{3} \cdot$ Lisa Lattanza $^{4}$ \\ Accepted: 9 September 2021 / Published online: 9 October 2021 \\ (C) The Author(s), under exclusive licence to Springer Science+Business Media, LLC, part of Springer Nature 2021
}

\begin{abstract}
Purpose of Review Orthopedic surgery lags behind the other surgical specialties in terms of reaching gender equality, and women remain underrepresented in the field. The reason for this disparity is multifaceted, with lack of exposure and mentorship frequently cited as two key reasons women fail to choose orthopedic surgery as a specialty. Recognizing these gender differences, The Perry Initiative was founded to increase young women's exposure to the field, provide mentorship opportunities, and recruit women into orthopedic surgery and related engineering fields. The purpose of this article is to describe the measurable impact of The Perry Initiative on increasing the number of women matriculating into orthopedic residencies.

Recent Findings Though roughly half of medical school graduates today are women, only $16 \%$ of active orthopedic surgery residents are women. To date, The Perry Initiative has reached over 12,000 women in high school and medical school, and of the program participants who are eligible to match into any residency program, $20 \%$ matched into orthopedic surgery residencies. Summary This indicates that the women who participated in Perry Initiative outreach programs are entering orthopedic surgery at a rate that is higher than the current rate of women entering orthopedic surgery. The model behind The Perry Initiative's outreach efforts can be scaled and expanded, ideally reaching more women and making progress towards closing the gender gap within orthopedic surgery and achieving greater gender diversity.
\end{abstract}

Keywords The Perry Initiative $\cdot$ Orthopedic surgery $\cdot$ Gender $\cdot$ Diversity $\cdot$ Women surgeons $\cdot$ Orthopedic education

This article is part of the Topical Collection on Gender and Racial Disparities

Lisa Lattanza

lisa.lattanza@yale.edu

Delaney Harbold

dharbold2@pennstatehealth.psu.edu

Laurie Dearolf

laurie@perryinitiative.org

Jennifer Buckley

jbuckley@udel.edu

Pennsylvania State College of Medicine, Hershey, PA 17033, USA

2 The Perry Initiative, Pittsburgh, PA, USA

3 Mechanical Engineering, Newark, DE 19716, USA

4 Department of Orthopaedics and Rehabilitation, Yale School of Medicine, 47 College Street, New Haven, CT 06511, USA

\section{Introduction}

The Perry Initiative is a nonprofit organization that was started in 2009 with a mission to increase young women's exposure to the fields of orthopedic surgery and engineering. The organization is committed to recruiting women into orthopedic surgery and related engineering fields and inspiring them to be leaders in these and similar underrepresented STEM disciplines [1]. This is accomplished by targeting women in high school and medical school, two crucial points along the pathway to a career in orthopedic surgery, through the Perry Outreach Program (POP) and the Medical Student Outreach Program (MSOP).

The premise behind creating programming for high school and medical students was based on literature citing that women fail to choose orthopedic surgery as a specialty based on lack of exposure [2-4]. Statistics show that men are more likely to know they want to go into orthopedic surgery prior to even entering medical school [4]. The founding members of The Perry Initiative recognized these gender differences and 
created this program in order to address them and make progress towards gender diversity within orthopedic surgery.

Great progress has been made with regard to gender equality in the field of medicine as a whole. In $2019,50.5 \%$ of students enrolled in medical school were women, and for the first time, women made up over half of currently enrolled medical students in the USA [5]. The percentage of women graduating medical school has more than doubled since the year 1980 [6]. However, this upward trend is not observed across all specialties within medicine. Orthopedic surgery is a field that is still lagging behind all other surgical specialties in terms of reaching gender equality. Though roughly half of medical school graduates today are women, only $16.0 \%$ of active orthopedic surgery residents for the 2019-2020 academic school year are women [7•], and only $6.5 \%$ of practicing orthopedic surgeons are women. In comparison, other surgical specialties are approaching a more equal gender distribution, with women representing $43.1 \%$ of current general surgery residents, and women making up $40.9 \%$ of current plastic surgery residents [7•] (Table 1 ).

Despite near equal rates of men and women graduating medical school and entering residency today, orthopedic surgery remains a male-dominated field. The root causes of this disparity are multifaceted. Rhode et al. conducted a survey of practicing female orthopedic surgeons who are members of the Ruth Jackson Orthopedic Society in order to identify reasons for choosing this specialty, as well as perceptions of the field they believe may deter women from pursuing orthopedic surgery. The most common reasons reported for why women do not pursue orthopedic surgery include the perceived inability to have work-life balance, the perception that it is too physically strenuous, and a lack of mentorship [2]. Furthermore, negative stereotypes surrounding orthopedics including the field having an "old boys club" mentality or "jock fraternity" culture have been said to play a role in deterring females from the specialty $[8,9]$. Though these assumptions are not necessarily based in fact, these and other misconceptions are prevalent along the pathway to choosing a specialty, which may discourage aspiring women physicians away from pursuing orthopedics.
The goals of The Perry Initiative are to dispel these myths and stereotypes, instill confidence, and provide exposure and mentorship. Jagsi et al. reported that women medical students were more likely to enter programs with higher rates of women residents, indicating that same-gender mentors and role models may be important in recruiting aspiring physicians to a given field [3]. Additionally, men were more likely to have already decided on pursuing orthopedic surgery prior to entering medical school and beginning clerkships, whereas women students are more likely to choose to pursue orthopedics later during their clinical rotations [4]. This implies that mentorship and exposure to orthopedics before and early on during medical school, prior to clinical rotations, is not only key for the decision to pursue orthopedics, but is something that can be capitalized on to recruit more aspiring women physicians to the field of orthopedic surgery.

The Perry Initiative's early impact on increasing gender diversity in orthopedic surgery residents was reported in an article titled The Perry Initiative's Medical Student Outreach Program Recruits Women into Orthopaedic Residency, by Lattanza et al [10•]. This article gives longer term follow-up on that initial report as well as new discussion on relevant statistics and interventions.

\section{Methods and Results}

Through partnerships with universities, medical centers, and high schools, The Perry Initiative hosts 70 programs annually, including around 45 programs for high school women and 25 programs for women in medical school, at 45 locations across the USA [1]. The Perry Outreach Program is a day-long career exploration workshop open to high school students who gender-identify as female, with an interest in orthopedic surgery and/or engineering. POP participants have the opportunity to hear and learn from leaders in the field of orthopedics and engineering, through lectures, panel discussions, and hands-on workshops including mock surgical procedures and biomedical engineering experiments. The program also provides participants with the opportunity to network and
Table 1 Gender representation of total active residents across surgical specialties for the 20192020 academic year. This includes all current residents who graduated from both MD and DO $[7 \bullet]$

\begin{tabular}{llll}
\hline $\begin{array}{l}\text { ACGME-accredited specialties and } \\
\text { subspecialties }\end{array}$ & $\begin{array}{l}\text { Total active } \\
\text { residents }\end{array}$ & $\begin{array}{l}\text { Total women } \\
\text { residents }\end{array}$ & $\begin{array}{l}\text { \% women } \\
\text { residents }\end{array}$ \\
\hline Surgery: general & 9,214 & 3,967 & $43.1 \%$ \\
Plastic surgery & 1157 & 473 & $40.9 \%$ \\
Otolaryngology & 1,639 & 623 & $38.0 \%$ \\
Urology & 1,673 & 461 & $27.6 \%$ \\
Thoracic surgery & 457 & 118 & $25.8 \%$ \\
Neurological surgery & 1,531 & 298 & $19.5 \%$ \\
Orthopedic surgery & 4,214 & 673 & $16.0 \%$ \\
\hline
\end{tabular}


connect with local mentors in the field. Additionally, The Perry Initiative has developed Orthopedics in Action, a curriculum for junior high and high school STEM classrooms. The kits include materials for physics and engineering experiments tailored for this age group that are conducted through the lens of orthopedic surgery. This program is a way to passively increase the exposure to orthopedics from an even earlier age.

The Medical Student Outreach Program is targeted for first year and second year women medical students across the country. The MSOP is a hands-on introduction to the field of orthopedic surgery that is led by female residents and attendings $[10 \bullet, 11]$. Participants have the opportunity to learn from local experts through lectures on topics including the following: a day in the life of an orthopedic surgeon, work-life balance, orthopedic subspecialties, and what is necessary to successfully match into orthopedic surgery residency [10•]. MSOP students participate in fracture case discussions and simulated orthopedic surgeries using Sawbones [10•]. In addition to the exposure and introduction to orthopedics, another goal of the MSOP is to connect participants with local mentors, as well as connect peers with similar interests and career aspirations.

Since its conception in 2009, The Perry Initiative has reached a total of over 12,000 women through the Perry Outreach Program and Medical Outreach Program, which is a number that is continuing to grow. The Perry Initiative has hosted 295 POP events to date, reaching a total of 9,768 participants. The Perry Initiative has hosted 133 MSOP events, reaching 2,178 participants. In 2020, The Perry Initiative pivoted during the COVID-19 pandemic and launched the Perry Virtual Experience, which has currently reached 537 participants through 14 sessions. The Perry Virtual Experience is an interactive online program including mock engineering experiments and orthopedic surgery simulations and is open to high school and college women. Though this program is new, it has the potential to reach many more women due to the virtual format and the ability for prospective participants to connect from any location (Table 2).

To gain insight into how many Medical Student Outreach Program participants have successfully matched into orthopedics, surveys were sent out to MSOP participants who are eligible to match into any specialty. Eighty-eight percent of the participants responded. Nine hundred and fifty-four

Table 2 Number of women reached through The Perry Initiative programs

\begin{tabular}{ll}
\hline Program & Participants \\
\hline POP & 9,768 \\
MSOP & 2,178 \\
Perry Virtual Experience & 537 \\
Total women reached & 12,483 \\
\hline
\end{tabular}

participants completed the survey, and of the 954 participants, 186 reported that they matched into orthopedics. This puts the match rate for Medical Student Outreach Program alumni at $20 \%$.

Additionally, a study conducted by Lattanza et al. found that according to program data, the MSOP improved participant's perceptions of orthopedic surgery as a profession and that the program positively influences women's choice to pursue orthopedic surgery $\left[10^{\bullet}\right]$.

\section{Discussion}

Through The Perry Initiative's Perry Outreach Program and Medical School Outreach Program, a total of 12,483 women in high school and medical school have been reached during pivotal times in the decision to pursue a given career path. The match rate for MSOP participants is $20 \%$, which is higher than the current percentage of women that are in orthopedic residencies [12]. This indicates that the women who participated in The Perry Initiative outreach programs have a rate of choosing orthopedic surgery that is higher than the national average of women choosing orthopedic surgery. Furthermore, survey data shows that the MSOP positively influenced participants' perceptions and interest in the field of orthopedics [10•].

One thing to note is that for the first time, residents who completed MD programs are counted together with residents who completed DO programs. This is due to the ACGME MD/DO Merger that occurred in 2020, which causes the current statistics on residents to appear different from this point forward than they have in previous years in terms of the number of active residents as well as their demographic data.

One limitation of this discussion is the lack of data on matriculation into orthopedics for alumni of the Perry Outreach Program and the Perry Virtual Experience, compared to the data available for the Medical School Outreach Program. This is because the participants of the POP are high school students, and the majority of participants still have many years of training to go before they have completed medical school and are eligible to match into residency. The match data for the first cohorts in 2009 is just recently becoming available over the last few years, as the path from high school to residency applications is 9 to 12 years long at minimum. Along the same lines, Perry Virtual Experience was implemented in 2020, so the first participants would not be eligible to apply for residencies for several more years. However, the effects of these initiatives will continue to be tracked, and the full impact of these programs will be seen over the years to come as participants progress through their high school, college, and medical school education and begin applying for residency.

Additionally, it is important to note the limitation of discussing gender in terms of the male vs female dichotomy. 
The available residency match data and statistics are reported in terms of male or female, which may fail to adequately represent all individuals, including those who are non-binary. A critical step towards achieving and promoting true gender diversity is using language as well as categories that are more inclusive.

Overall, despite the near equal numbers of men and women in medical school today, orthopedic surgery is still a field that is strikingly male-dominated. The reasons for this are multifaceted, but some of the most commonly cited reasons as to why this may be the case include the perceived lack of work/life balance, the idea that it is too physically demanding, lack of mentorship and exposure, and negative stereotypes and culture associated with the field $[1,8,9]$. Though these reasons are discouraging, the positive news is that there are opportunities for intervention at multiple steps along the path to choosing to pursue orthopedics as a specialty, from junior high through medical school.

The Mansfield Rule outlines that if a minority group, whether it is gender, ethnicity, or sexual orientation, reaches $30 \%$ of a population, a critical mass for disrupting bias and achieving and maintaining diversity has been attained [13]. The Mansfield Rule has historically been applied to the fields of law, sociology, and anthropology but may have applications in medicine as well. In fact, the Mansfield Rule has been demonstrated to be true within the medical specialty of general surgery. General surgery is another field that has been male-dominated throughout history, with females making up only $1.4 \%$ of active general surgeons in 1981 [14]. However, the percentage of female general surgery trainees has been increasing over time, rising to $21.2 \%$ in 1999 and then to $35.2 \%$ in 2009 , overcoming the critical mass outlined by the Mansfield Rule [15]. Since overcoming that $30 \%$ threshold, the rate of women entering general surgery residencies has only sustained this upward trend, with women accounting for $41.3 \%$ general surgery residents in the 2018-2019 academic year [7]. Through the Perry Initiative and related efforts dedicated to increasing the number of women who matriculate into orthopedic surgery towards the milestone of $30 \%$ women in the field may also be achieved, and progress towards gender equity within orthopedic education will continue to be seen.

Organizations such as The Perry Initiative provide targeted outreach efforts, early exposure to the field, and mentorship, which is an important piece of recruiting more women orthopedic surgeons and dismantling some of the negative perceptions early on. The model and concepts behind The Perry Initiative can be scaled and expanded, reaching and recruiting more women to orthopedic surgery. This will ideally have downstream effects including making progress towards closing the gender gap and achieving greater gender diversity, so the brightest and most talented students are recruited to the field, regardless of their gender identity, so that the orthopedic surgery workforce more closely resembles the patients that they serve.

\section{Declarations}

Human and Animal Rights and Informed Consent This article does not contain any studies with human or animal subjects performed by any of the authors.

Conflict of Interest Delaney Harbold, Dr. Laurie Dearolf-Meszaros, Dr. Jennifer Buckley, and Dr. Lisa Lattanza declare that they have no conflicts of interest.

\section{References}

Papers of particular interest, published recently, have been highlighted as:

- Of importance

1. The Perry Initiative. Program Description. https://perryinitiative. org/outreach-programs/. Accessed Nov 2020.

2. Rohde RS, Wolf JM, Ädams JE. Where are the women in orthopaedic surgery? Clin Orthop Relat Res. 2016;474:1950-6. https:// doi.org/10.1007/s11999-016-4827-y.

3. Jagsi R, Griffith K, DeCastro R, Ubel P. Sex, role models, and specialty choices among graduates of US medical schools in 2006-2008. J Am Coll Surg. 2013;218(3):345-52. https://doi.org/ 10.1016/j.jamcollsurg.2013.11.012.

4. Bernstein J, Dicaprio MR, Mehta S. The relationship between required medical school instruction in musculoskeletal medicine and application rates to orthopaedic surgery residency programs. J Bone Joint Surg Am. 2004;86(10):2335-8. https://doi.org/10.2106/ 00004623-200410000-00031.

5. The Association of American Medical Colleges. The majority of U. S. medical students are women, new data show. https://www.aamc. org/news-insights/press-releases/majority-us-medical-students-arewomen-new-data-show (2010). Accessed Nov 2020.

6. The Association of American Medical Colleges. Current trends in medical education. https://www.aamcdiversityfactsand figures2016.org/report-section/section-3/\#figure-16 (2016). Accessed Nov 2020.

7. The Association of American Medical Colleges. Report on residents: 2019-20 active residents. https://www.aamc.org/datareports/students-residents/interactive-data/report-residents/2020/ table-b3-number-active-residents-type-medical-school-gmespecialty-and-sex (2020). Accessed Jan 2021. Above source is important as it is the source of the current residency data and gender distribution

8. Miller EK, LaPorte DM. Barriers to women entering the field of orthopedic surgery. Orthopedics. 2015;38(9):530-3. https://doi. org/10.3928/01477447-20150902-03.

9. Lillemoe KD, Ahrendt GM, Yeo CJ, Herlong HF, Cameron JL. Surgery-still an "old boys' club"? Surgery. 1994116(2):255-9. PMID: 8047993.

10. Lattanza LL, Meszaros-Dearolf L, O'Connor MI, et al. The perry initiative's medical student outreach program recruits women into orthopaedic residency. Clin Orthop Relat Res. 2016;474(9): 1962-1966. https://doi.org/10.1007/s11999-016-4908-y. Above article is important, and includes information on the early impact of The Perry Initiative 
11. The Perry Initiative. Medical Student Outreach Program. https:// perryinitiative.org/more-about-the-msop/. Accessed Nov 2020.

12. Okike K, Phillips DP, Swart E, O'Connor MI. Orthopaedic faculty and resident sex diversity are associated with the orthopaedic residency application rate of female medical students. J Bone Jt Surg. 2019;101(12):e56. https://doi.org/10.2106/JBJS.18.00320.

13. Mansfield Rule $4.0 \mathrm{https} / / / \mathrm{www}$.diversitylab.com/mansfield-rule4-0/. Accessed Dec 2020

14. Christian Lynge D, Larson EH, Thompson MJ, Rosenblatt RA, Hart LG. A longitudinal analysis of the general surgery workforce in the United States, 1981-2005. Arch Surg. 2008;143(4):345-50. https://doi.org/10.1001/archsurg.143.4.345.

15. Bulletin of the American College of Surgeons. Emamaullee JA, Lyons MD, Berdan E, Bazzarelli A. Women leaders in surgery: past, present, and future. https://bulletin.facs.org/2012/08/womenleaders-in-surgery-past-present-and-future/ (2012) Accessed Jan 2021

Publisher's note Springer Nature remains neutral with regard to jurisdictional claims in published maps and institutional affiliations. 